\title{
Kajian Sistem Pemurnian Helium Reaktor HTGR Berdaya Kecil
}

\author{
Siti Alimah ${ }^{\star 1}$, Sriyono ${ }^{2}$ \\ ${ }^{1}$ Pusat Kajian Sistem Energi Nuklir (PKSEN)-BATAN,Jl. Kuningan Barat, Jakarta Selatan, Indonesia \\ ${ }^{2}$ Pusat Teknologi dan Keselamatan Reaktor Nuklir (PTKRN)-BATAN, Gedung 80, Kawasan Puspitek, Tangsel, Indonesia
}

\begin{tabular}{l}
\hline INFORMASI ARTIKEL \\
\hline Riwayat Artikel: \\
Diterima: \\
11 Januari 2016 \\
Diterima dalam bentuk revisi: \\
11 Maret 2016 \\
Disetujui: \\
11 Mei 2016 \\
\end{tabular}

Kata kunci:

Sistem pemurnian helium

Pengotor

Pendingin primer

HTGR berdaya kecil

\begin{abstract}
ABSTRAK
KAJIAN SISTEM PEMURNIAN HELIUM REAKTOR HTGR BERDAYA KECIL. Sistem pemurnian helium (SPH) adalah salah satu sistem keselamatan pada reaktor HTGR. SPH berfungsi membersihkan pengotor yang ada pada pendingin primer, sehingga dampak terhadap struktur, sistem dan komponen (SSK) reaktor minimal. Ada dua jenis pengotor pada pendingin yaitu berbentuk partikulat (debu karbon, produk fisi $\left(\mathrm{Kr}, \mathrm{Xe}, \mathrm{Cs}\right.$, dll.)) dan gas $\left(\mathrm{O}_{2}, \mathrm{~N}_{2}, \mathrm{H}_{2} \mathrm{O}, \mathrm{CH}_{4}\right.$, $\mathrm{CO}, \mathrm{CO}_{2}$, dan $\mathrm{H}_{2}$ ). Setiap reaktor mempunyai batasan pengotor yang berbeda selama operasi normal tergantung pada daya reaktor, sistem konversi energi dan jenis bahan bakar yang digunakan. Makalah ini membahas SPH pada HTR-10, HTTR dan desain konseptual RDE. Tujuan kajian adalah mengetahui desain SPH yang optimum dan dapat digunakan sebagai masukan desain SPH RDE. Metodologi yang digunakan adalah kajian literatur berdasarkan pengalaman operasi HTR-10 dan HTTR serta evaluasi desain konseptual RDE. Parameter kajian ditekankan pada batasan pengotor yang dipersyaratkan pada operasi normal, komponen utama alat pemurnian, laju alir masa dan proses regenerasi. Komponen utama peralatan pemurnian yang digunakan pada SPH HTR-10, HTTR dan RDE adalah sama yaitu filter, kolom $\mathrm{CuO}$, water cooler, kolom molecular sieve dan karbon aktif kondisi kriogenik. Berdasarkan pengalaman operasi HTR-10 dan HTTR, desain SPH yang digunakan cukup handal dalam menjaga kemurnian pendingin primer, meskipun batasan pengotor yang ditetapkan berbeda. SPH pada HTTR Jepang memiliki penetapan batas yang lebih ketat yaitu tidak boleh ada pengotor $\mathrm{N}_{2}, \mathrm{CH}_{4}$ dan $\mathrm{O}_{2}$ pada operasi normal, serta menggunakan precharcoal trap untuk mengadsorpsi debu halus dibawah 0,1 mikron. Kedua parameter ini dapat diadopsi pada desain SPH RDE agar dampak pengotor terhadap SSK minimal.
\end{abstract}

\section{ABSTRACT}

THE ASSESSMENT OF HELIUM PURIFICATION SYSTEM OF SMALL POWER HTGR. The helium purification system (HPS) is one of safety system of High Temperature Gas-cooled Reactor. HPS removes impurities in the primary coolant, so that the impact on structure, system and component (SSC) is minimized. The two impurity types are particulates (carbon dust, fission products $\left(\mathrm{Kr}, \mathrm{Xe}\right.$, Cs etc.) and the gases $\left(\mathrm{O}_{2}, \mathrm{~N}_{2}, \mathrm{H}_{2} \mathrm{O}, \mathrm{CH}_{4}, \mathrm{CO}, \mathrm{CO}_{2}\right.$, and $\left.\mathrm{H}_{2}\right)$. Every reactor has a different impurity limit during normal operation, depends on the reactor power, energy conversion system and fuel type. This paper discusses the HPS on HTR-10, HTTR and Indonesian RDE conceptual design. The purpose of this assessment is to determine the optimum HPS design as a role model for Indonesian RDE. The utilized methodology is a literature study based on the operating experiences of both HTR-10 and HTTR as well as the evaluation of RDE conceptual design. This study focuses on the impurities limit during normal operation, the main components of HPS, mass flow-rate and regeneration process. The main component that used in HPS for HTR-10, HTTR and RDE are similar i.e. filter, CuO column, water cooler, molecular sieve bed and cryogenic activated carbon bed. Refer to the HTR-10 and HTTR operational experiences, both of those reactors have a purification systems that capable to maintain the helium purity, eventhough the impurities limit are different. The HPS of HTTRJapan has a stricter impurities limit that $\mathrm{N}_{2}, \mathrm{CH}_{4}$, and $\mathrm{O}_{2}$ should not be contained at all during normal operation and the precharcoal trap is used to adsorb the fine dust below 0.1 micron. Both of these parameters can be adopted to the RDE's HPS design to minimize the effect of impurities to SSC.

Keywords: helium purification system, impurities, primary coolant, small power HTGR.

\section{PENDAHULUAN}

High Temperature Gas Cooled Reactor (HTGR) adalah reaktor temperatur tinggi yang menggunakan gas helium sebagai

${ }^{*}$ Penulis korespondensi.

E-mail: alimahs@batan.go.id pendingin[1]. Gas helium digunakan sebagai pendingin karena karakteristiknya sebagai gas ideal/gas inert, tidak mengalami perubahan sifat fisik maupun kimia pada temperatur sangat tinggi, tidak bereaksi dengan gas/zat 
lain, efektif untuk keperluan perpindahan panas dan mudah dimampatkan sampai lebih dari $5 \mathrm{MPa}$ [2]. Kemurnian gas helium sebagai pendingin HTGR harus dijaga, baik dari pengotor yang berbentuk partikulat maupun gas [3]. Pengotor partikulat adalah debu karbon yang mempunyai kemungkinan bercampur dengan produk fisi, sedangkan pengotor berbentuk gas adalah $\mathrm{O}_{2}, \mathrm{~N}_{2}, \mathrm{H}_{2} \mathrm{O}$, $\mathrm{CH}_{4}, \mathrm{CO}, \mathrm{CO}_{2}$, dan $\mathrm{H}_{2}[4]$.

Sumber pengotor debu karbon terutama berasal dari gesekan bahan bakar di dalam teras (jika menggunakan bahan bakar pebble) [5] dan gesekan aliran gas helium dengan blok bahan bakar (jika menggunakan bahan bakar prismatik) [6]. Pengotor berbentuk gas berasal dari interaksi antara air $\left(\mathrm{H}_{2} \mathrm{O}\right)$ atau udara dengan grafit $[6,7] . \mathrm{H}_{2} \mathrm{O}$ dapat masuk ke sistem pendingin primer akibat adanya water ingress. Water ingress dapat terjadi pada saat kebocoran tabung steam generator. Sedangkan Air ingress (intrusi udara) dimungkinkan terjadi pada saat perawatan, karena pada saat pembongkaran komponen atau sistem pipa primer, dimungkinkan udara masuk ke pendingin primer cukup besar meskipun pada proses pembongkaran tersebut sudah digunakan peralatan pembungkus (envelope). Saat operasi, udara yang masuk berinteraksi dengan grafit. Udara yang masuk ke sistem pendingin primer mengandung $\mathrm{H}_{2} \mathrm{O}$ meskipun dalam jumlah kecil karena faktor kelembabannya[8]. Setelah berinteraksi dengan grafit di dalam teras, maka akan terbentuk gas pengotor $\mathrm{CO}, \mathrm{H}_{2}, \mathrm{CO}_{2}$, dan $\mathrm{CH}_{4}$, yang reaksinya adalah sebagai berikut :

$$
\begin{aligned}
& \mathrm{C}+\mathrm{H}_{2} \mathrm{O} \rightarrow \mathrm{CO}+\mathrm{H}_{2} \\
& \mathrm{C}+1 / 2 \mathrm{O}_{2} \rightarrow \mathrm{CO} \\
& 1 / 2 \mathrm{O}_{2}+\mathrm{CO} \rightarrow \mathrm{CO}_{2} \\
& \mathrm{C}+\mathrm{CO}_{2} \rightarrow 2 \mathrm{CO} \\
& \mathrm{C}+2 \mathrm{H}_{2} \rightarrow \mathrm{CH}_{4} \\
& 2 \mathrm{C}+2 \mathrm{H}_{2} \mathrm{O}+\mathrm{H}_{2} \rightarrow \mathrm{CH}_{4}+\mathrm{CO}
\end{aligned}
$$

Gas $\mathrm{N}_{2}$ sudah ada dalam udara, sehingga ketika terjadi kebocoran, maka $\mathrm{N}_{2}$ akan terbawa masuk ke pendingin.

Pengotor gas helium harus dibersihkan karena memberikan dampak negatif pada struktur, sistem dan komponen (SSK) reaktor. Pengotor debu karbon yang terbawa dalam aliran pendingin akan menempel pada permukaan SSK dan mengakibatkan penurunan kemampuan perpindahan panas. Jika pengotor debu karbon bercampur dengan produk fisi dan terdeposisi pada permukaan SSK maka dapat meningkatkan paparan radiasi ke lingkungan dan pekerja $[10,11]$. Gas pengotor pada pendingin helium jika melebihi batas yang

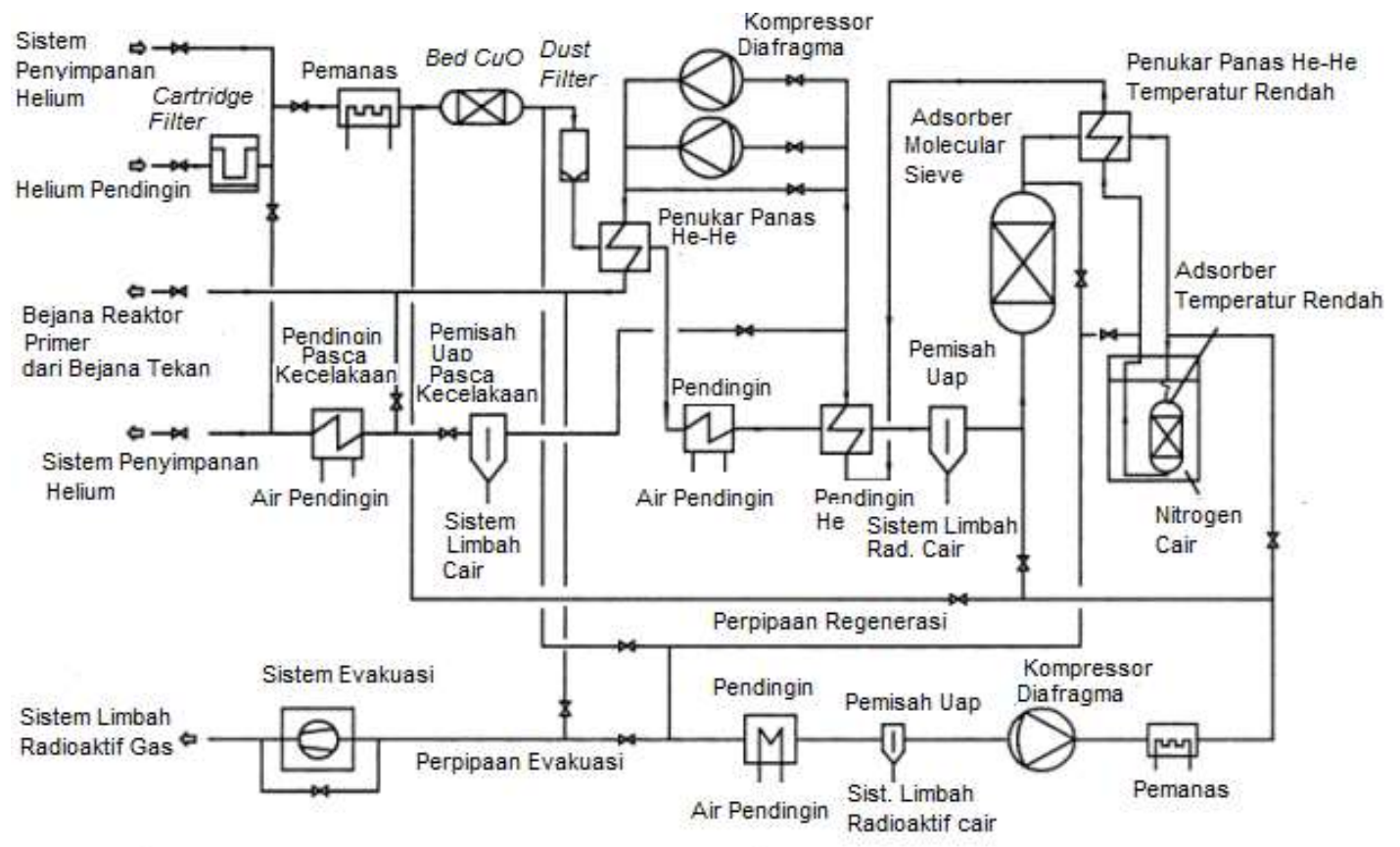

Gambar 1. Diagram Skematik Sistem Pemurnian Helium HTR-10 [17]. 
diijinkan, selain akan berdampak pada peningkatan paparan radiasi, juga menimbulkan korosi grafit, proses karburisasi dan dekarburisasi pada SSK [12].

Sistem Pemurnian Helium (SPH) pada reaktor HTGR mempunyai fungsi utama untuk mempertahankan/menjaga kualitas helium pendingin sesuai dengan persyaratan yang telah ditetapkan [13]. Sistem ini terdiri dari komponen utama: filter, kolom oksidasi $\mathrm{CuO}$, kondensor (water cooler), kolom molecular sieve dan kolom karbon aktif temperatur sangat rendah (cryogenic). Pada $\mathrm{SPH}$, filter atau cartridge filter berfungsi menyaring debu karbon, kolom oksidasi $\mathrm{CuO}$ berfungsi mengoksidasi $\mathrm{CO}$ menjadi $\mathrm{CO}_{2}$ dan $\mathrm{H}_{2}$ menjadi $\mathrm{H}_{2} \mathrm{O}$, dengan katalis $\mathrm{CuO}$. Air atau $\mathrm{H}_{2} \mathrm{O}$ akan dipisahkan dengan pengembunan menggunakan kondensor yang dipasang setelah kolom $\mathrm{CuO}$. Kolom molecular sieve berfungsi menyerap $\mathrm{CO}_{2}, \mathrm{CH}_{4}$, dan $\mathrm{H}_{2} \mathrm{O}$ [14]. Kolom karbon aktif yang dikondisikan beroperasi pada temperatur yang sangat rendah $-180^{\circ} \mathrm{C} \quad$ (kriogenik) berfungsi menyerap $\mathrm{CH}_{4}$, gas mulia (Xe, $\mathrm{Kr}$ ), $\mathrm{H}_{2}, \mathrm{~N}_{2}$ dan produk fisi lainnya yang dihasilkan dari teras reaktor [15].

Saat ini, Indonesia berencana membangun dan mengoperasikan Reaktor
Daya Eksperimental (RDE) yang menggunakan reaktor jenis HTGR dan direncanakan berdaya kecil yaitu $10 \mathrm{MW}_{\text {th }}$. Beberapa reaktor HTGR daya kecil yang telah mempunyai pengalaman operasi adalah HTR-10 (High Temperature Reactor $10 \mathrm{MW}$ ) China dan HTTR (High Temperature Engineering Tested Reactor) Jepang. Masing-masing reaktor tersebut mempunyai SPH yang berbeda dengan batas kendali gas pengotor pada pendingin primer juga berbeda. Makalah ini bertujuan untuk mengetahui desain SPH yang optimum dan dapat digunakan sebagai masukan desain SPH RDE. Ketiga reaktor tersebut dikategorikan berdaya kecil karena dayanya $<300 \mathrm{MW}_{\mathrm{e}}$. HTR-10 China dan RDE adalah reaktor yang berdaya $10 \mathrm{MW}_{\text {th }}$, sedangkan HTTR berdaya $30 \mathrm{MW}_{\text {th. }}$ Sebagaimana HTR-10, RDE direncanakan menggunakan bahan bakar pebble, sedangkan HTTR menggunakan bahan bakar prismatik. Ketiga reaktor menggunakan sistem konversi energi tidak langsung (indirect cycle) [1,6], dengan penggunaan steam generator/ intermediate heat exchanger sebagai komponen pemindah panas dari sistem pendingin primer ke sistem pendingin sekunder. Media dalam sistem pendingin primer adalah gas helium sedangkan pada sistem pendingin sekunder adalah air/steam.

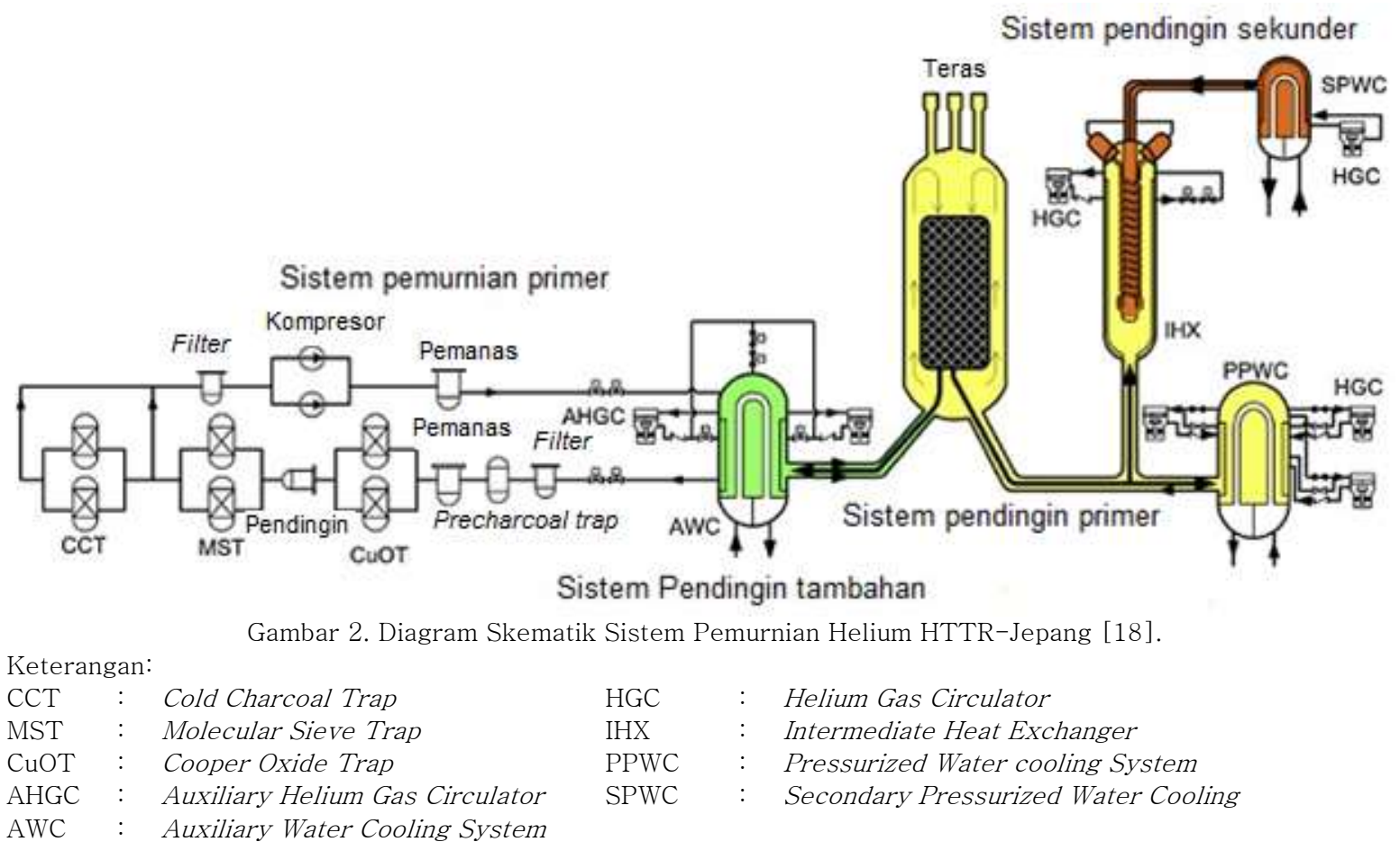


Komponen SPH yang dibahas hanya komponen utama pemurnian, tidak termasuk komponen bantu seperti compressor, heater/cooler, katup dan lain-lain. Laju alir (mass flow rate) pada inlet SPH adalah faktor penting kajian karena berdampak pada kemampuan SPH dalam membersihkan keseluruhan massa helium dalam pendingin reaktor selama rentang siklus operasi tertentu. Hasil purifikasi dari SPH akan dikembalikan ke sistem pendingin primer untuk disirkulasi kembali mengambil panas teras reaktor. Hasil kajian diharapkan dapat memberi masukan dalam perbaikan desain SPH RDE yang direncanakan akan dibangun di Indonesia

\section{METODOLOGI}

Metodologi yang digunakan adalah kajian literatur berdasarkan pengalaman operasi HTR-10, HTTR dan evaluasi desain konseptual RDE. Kajian dilakukan terhadap SPH dari masing-masing reaktor. Analisis dilakukan terhadap beberapa parameter, dengan membandingkan masing-masing SPH tersebut, sehingga dapat diketahui desain $\mathrm{SPH}$ yang memiliki kelebihan dalam membatasi jumlah gas pengotor pada pendingin, sehingga keandalan SSK terjamin. Parameter kajian adalah komponen utama pemurnian yang digunakan, laju alir massa (mass flow-rate) pada aliran masuk ke SPH, proses regenerasi ketika komponen yang digunakan sudah mengalami kejenuhan dan batasan gas pengotor yang dipersyaratkan pada kondisi operasi normal.

\section{SISTEM PEMURNIAN HELIUM (SPH) REAKTOR HTGR}

\subsection{SPH HTR-10 China}

HTR-10 China adalah reaktor berdaya $10 \mathrm{MW}_{\text {th }}$, mencapai kritis pertama kali tahun 2000. Reaktor ini telah digunakan untuk eksperimen selama 3 tahun. Reaktor HTR-10 menggunakan siklus tak langsung, dengan pendingin primer adalah gas helium dan pendingin sekunder adalah air. HTR-10 menggunakan bahan bakar pebble. Diagram skematik SPH pada HTR-10 ditunjukkan pada Gambar $1[16,17]$.

Ada 5 komponen utama pada SPH HTR10 yaitu filter (cartridge filter), kolom oksidator

$\mathrm{CuO}$, water cooler, kolom molecular sieve dan karbon aktif kriogenik. Pada operasi normal, aliran inlet $\mathrm{SPH}$ adalah aliran bypass dari pendingin primer pada lokasi setelah compressor/circulator pada temperatur $250^{\circ} \mathrm{C}$ dan tekanan 3,0 MPa. SPH ini mengambil 5\% volume pendingin primer untuk dimurnikan dengan laju alir sebesar 10,5 kg/jam. Konstanta pemurnian adalah sebesar 0,05 per jam. SPH mempunyai satu buah train yang terdiri dari rangkaian komponen untuk kondisi operasi normal dan kecelakaan. Kedua komponen ini menyatu dalam satu buah rangkaian (train), meskipun untuk komponen kecelakaan diberi nama komponen pasca kecelakaan (post accident) [17].

Tabel 1. Batasan Konsentrasi Gas Pengotor Pendingin HTR-10 pada Operasi Normal [17]

\begin{tabular}{ccc}
\hline No. & Gas Pengotor & Batasan $\left(\mathrm{cm}^{3} \cdot \mathrm{m}^{-3}\right)$ \\
\hline 1 & $\mathrm{H}_{2} \mathrm{O}$ & $\leq 0,2$ \\
2 & $\mathrm{CO}$ & $\leq 3,0$ \\
3 & $\mathrm{~N}_{2}$ & $\leq 1,0$ \\
4 & $\mathrm{H}_{2}$ & $\leq 3,0$ \\
5 & $\mathrm{CH}_{4}$ & $\leq 1,0$ \\
\hline
\end{tabular}

Pada operasi normal, batasan maksimum gas pengotor yang diijinkan pada pendingin HTR-10 ditunjukkan pada Tabel 1. Setelah melalui SPH, gas helium yang telah bersih akan diinjeksikan kembali ke pendingin primer. Temperatur gas helium keluaran SPH akan dinaikkan dengan electrical heater dari $-160^{\circ} \mathrm{C}$ menjadi $185^{\circ} \mathrm{C}$ [17]. Titik pengambilan aliran masuk ke SPH adalah titik setelah steam generator dan titik penginjeksian adalah sebelum steam generator.

Regenerasi dilakukan setelah mengalami kejenuhan dan berdasar pengalaman setelah beroperasi 2000 jam [17]. Proses ini akan dilakukan jika pengukuran keluaran SPH batasnya terlampaui. Jika terjadi kecelakaan kebocoran air, maka aliran akan di bypass ke komponen pasca kecelakaan yang terdiri dari pendingin air (kondensor) dan moisture separator (pemisah uap). Air yang terpisahkan kemudian dikelola sebagai limbah cair. Gas helium bersih kemudian dialirkan kembali ke 
train normal operasi untuk membersihkan sisa gas pengotor.

\subsection{SPH HTTR-Jepang}

HTTR Jepang adalah reaktor berbasis teknologi HTGR dengan daya $30 \mathrm{MW}_{\text {th }}$, dengan

Tabel 2. Batasan Konsentrasi Gas Pengotor Pendingin HTTR pada Operasi Normal $900^{\circ} \mathrm{C}[18]$

\begin{tabular}{lcc}
\hline No. & Pengotor & Batasan $\left(\mathrm{cm}^{3} \cdot \mathrm{m}^{-3}\right)$ \\
\hline 1 & $\mathrm{H}_{2} \mathrm{O}$ & $\leq 0,2$ \\
2 & $\mathrm{CO}$ & $\leq 3,0$ \\
3 & $\mathrm{H}_{2}$ & $\leq 3,0$ \\
4 & $\mathrm{CO}_{2}$ & $\leq 0,6$
\end{tabular}

temperatur keluaran teras mencapai $950^{\circ} \mathrm{C}$ [18]. Bahan bakar yang digunakan adalah jenis prismatik [19,20]. Gas pengotor yang terjadi pada pendingin primer adalah $\mathrm{O}_{2}, \mathrm{~N}_{2}$, $\mathrm{H}_{2} \mathrm{O}, \mathrm{CH}_{4}, \mathrm{CO}, \mathrm{CO}_{2}$, dan $\mathrm{H}_{2}$ [18]. Gas ini berasal dari reaksi air/udara yang masuk ke pendingin primer dengan komponen grafit dari

Tabel 3. Batasan Konsentrasi Gas Pengotor pada Pendingin Primer RDE pada Operasi Normal [25]

\begin{tabular}{ccc}
\hline No. & Pengotor & Batasan $\left(\mathrm{cm}^{3} \cdot \mathrm{m}^{-3}\right)$ \\
\hline 1 & $\mathrm{H}_{2} \mathrm{O}$ & $\leq 0,2$ \\
2 & $\mathrm{CO}$ & $\leq 3$ \\
3 & $\mathrm{~N}_{2}$ & $\leq 0,2$ \\
4 & $\mathrm{H}_{2}$ & $\leq 3$ \\
5 & $\mathrm{CH}_{4}$ & $\leq 0,5$ \\
6 & $\mathrm{CO}_{2}$ & $\leq 0,6$ \\
7 & $\mathrm{O}_{2}$ & $\leq 0,02$ \\
\hline
\end{tabular}

teras reaktor, dan insulasi termal pada coaxial duct (bejana penghubung teras dengan komponen primer) [21]. Pada HTTR, gas pengotor harus diantisipasi untuk mencegah korosi grafit di teras dan proses dekarburisasi di tabung intermediate heat exchanger (IHX) yang terbuat dari bahan Hastelloy-XR dan beroperasi pada temperatur tinggi [22,23]. SPH pada HTTR dinamakan Primary Helium Purification System (PHPS) seperti ditunjukkan pada Gambar 2. PHPS terdiri dari sistem pemurnian dan regenerasi.

Komponen utama pada PHPS adalah filter, copper oxide trap (CuOT), molecular sieve trap (CuOT), cooler/water cooler, cold charcoal trap (CCT) [18]. Pada PHPS dilengkapi dengan precharcoal trap, setelah filter pertama. Kedua komponen tersebut menyaring debu grafit yang terbawa dalam pendingin. Kolom $\mathrm{CuOT}$ diisi dengan pelet $\mathrm{CuO}$ yang berfungsi mengoksidasi $\mathrm{CO}$ menjadi $\mathrm{CO}_{2}$ dan $\mathrm{H}_{2}$ menjadi $\mathrm{H}_{2} \mathrm{O}$, kedua pengotor ini akan diadsorpsi oleh molecular sieve. Untuk meningkatkan proses adsorpsi, maka pada aliran sebelum masuk ke molecular sieve, didinginkan dengan cooler/water cooler (pendingin). Tahapan terakhir pada PHPS adalah proses adsorpsi gas $\mathrm{N}_{2}$ dan $\mathrm{O}_{2}$. Proses ini dilakukan oleh kolom charcoal yang dialiri nitrogen cair untuk mendinginkan, sehingga temperaturnya menjadi $-180^{\circ} \mathrm{C}$. Batas gas pengotor yang diijinkan pada operasi normal $\left(900^{\circ} \mathrm{C}\right)$ reaktor HTTR Jepang ditunjukkan pada Tabel 2.

Pada masing-masing komponen PHPS dipasang komponen redundancy untuk proses regenerasi. Ketika satu komponen diregenerasi maka aliran dipindahkan ke komponen siaga (standby).

\subsection{Desain Konseptual SPH RDE}

Saat ini, Indonesia berencana membangun dan mengoperasikan RDE, dengan daya reaktor $10 \mathrm{MW}_{\text {th }}\left(3 \mathrm{MW}_{\mathrm{e}}\right)$, didesain berbasis teknologi HTGR, menggunakan bahan bakar pebble dan siklus tak langsung. Dari hasil analisis teknologi berdasar aspek strategi nasional dan aspek tekno ekonomi, pada studi yang telah dilakukan sebelumnya, HTGR yang menggunakan bahan bakar pebble memiliki nilai lebih unggul dibanding HTGR yang menggunakan bahan bakar prismatik. Analisis yang telah dilakukan tersebut dengan membuat nilai bobot, dan untuk aspek strategi nasional meliputi tujuan PLTN dibangun, rating daya pembangkit dan ketersediaan teknologi fabrikasi elemen bakar. Sedangkan aspek tekno-ekonomi meliputi keselamatan umum, teknologi teruji, kinerja pembangkit, kemudahan produksi elemen bakar, umur desain, interval siklus pengisian bahan bakar, efisiensi thermal, penyederhaan, kemudahan operasi dan perawatan serta proteksi fisik [24]. Berdasar desain konseptual RDE yang telah dibuat oleh BATAN, gas helium digunakan sebagai pendingin primer dan air digunakan sebagai pendingin sekunder $[25,26]$. Panas pendingin primer dipindahkan ke pendingin sekunder melalui steam generator. SPH RDE terdiri dari dua buah train yaitu train pertama digunakan untuk operasi normal dan train kedua digunakan untuk kondisi kecelakaan. Train SPH RDE juga mempunyai sistem regenerasi. Desain SPH pada RDE ditunjukkan pada Gambar 3 [25]. 


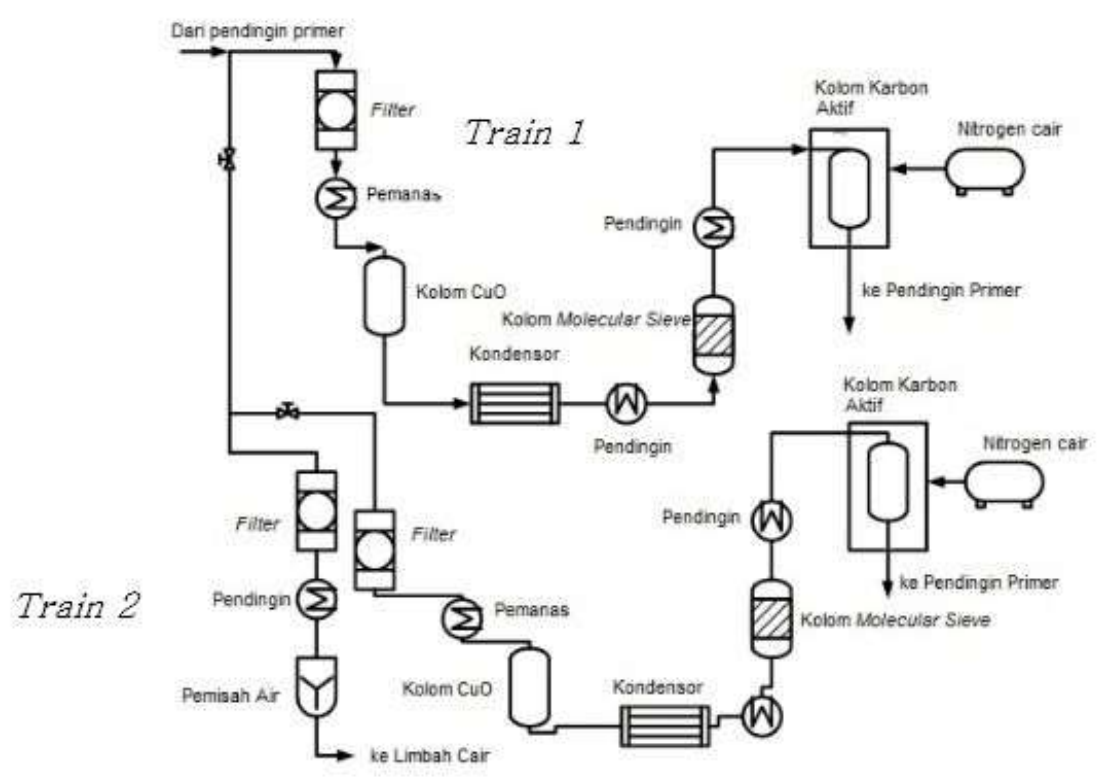

Gambar 3. Desain Sistem Pemurnian Helium pada Reaktor RDE [25].

Komponen utama yang digunakan pada SPH RDE adalah filter, kolom $\mathrm{CuO}$, kolom molecular sieve dan bed karbon aktif kriogenik. Batasan konsentrasi gas pengotor dari SPH RDE ditunjukkan pada Tabel 3 dan spesifikasi teknis train pertama dan kedua SPH RDE ditunjukkan pada Tabel 4.

Tabel 4. Spesifikasi Teknis Train Pertama dan Kedua SPH RDE [25,27]

\begin{tabular}{lll}
\hline \multicolumn{1}{c}{ Prain 1} & & \multicolumn{1}{c}{ Nilai } \\
\hline \multicolumn{1}{c}{ Parameter } & $:$ & $1-39 \mathrm{bar}$ \\
\hline Tekanan inlet & $:$ & $-180 \mathrm{~s} . \mathrm{d} 300{ }^{\circ} \mathrm{C}$ \\
Temperatur inlet & $:$ & $0,05 / \mathrm{jam}$ \\
Laju fraksi pemurnian dari seluruh volum inventori (konstanta purifikasi) & $:$ & $\sim 10,5 \mathrm{~kg} / \mathrm{jam}$ \\
Laju aliran masa pemurnian helium pada operasi normal $\left(250^{\circ} \mathrm{C}, 30 \mathrm{bar}\right)$ & $:$ & $1000 \mathrm{jam}$ \\
\hline Satu siklus operasi (sebelum regenerasi) & $:$ & $1-39 \mathrm{bar}$ \\
\hline Train 2 & $:$ & $30-300{ }^{\circ} \mathrm{C}$ \\
\hline Tekanan inlet & $:$ & $1 / \mathrm{jam}$ \\
Temperatur inlet & $:$ & $\sim 245 \mathrm{~kg} / \mathrm{jam}$ \\
Laju pemurnian dari seluruh inventori (konstanta purifikasi) & $:$ \\
Laju aliran masa pemurnian & . \\
\hline
\end{tabular}

\section{HASIL DAN PEMBAHASAN}

Pengotor pada pendingin reaktor berbasis desain HTGR yang berbentuk partikel padatan ataupun gas harus dibersihkan karena berdampak negatif pada SSK reaktor. Partikel debu karbon yang bercampur dengan produk fisi jika menempel pada SSK akan meningkatkan paparan radiasi ke lingkungan, sehingga hal ini harus dihindari. Proses pembersihan dilakukan dengan penyaringan pada SPH. Berdasarkan pengalaman operasi HTGR di dunia, debu karbon yang dihasilkan dari HTGR ukurannya bervariasi dari 0,1 mikron sampai dengan 10 mikron [6,7]. Filter yang dapat digunakan dapat berupa filter High Efficiency Particulate Air (HEPA) atau cartridge filter yang berisi microporous filter. Pada desain HTGR dengan siklus konversi energi langsung (direct cycle) seperti Pebble 
Bed Modular Reactor (PBMR), sebelum proses penyaringan dengan HEPA, debu berukuran besar (5-10 mikron) akan dipisahkan terlebih dahulu dengan cyclone separator. Sedangkan pada reaktor HTGR berdaya kecil seperti HTR-10 China dan HTTR Jepang dengan siklus tidak langsung, tidak membutuhkan cyclone separator terlebih dahulu, karena ukuran debu karbon yang terjadi lebih halus, dengan ukuran 0,1-5 mikron $[7,17,18]$.

Pada desain HTTR yang menggunakan bahan bakar prismatik, debu karbon yang dihasilkan jauh lebih sedikit dibandingkan dengan HTGR yang menggunakan bahan bakar pebble. Debu yang terbawa dalam aliran pendingin biasanya bercampur dengan produk fisi. Berdasarkan pengalaman operasi HTR-10 China, debu karbon yang dihasilkan adalah sekitar 2,74 kg/tahun [7], sedangkan debu karbon yang dihasilkan oleh HTTR Jepang adalah 2,5 kg per tahun [17]. Pada SPH kedua reaktor ini debu karbon dibersihkan dengan cartridge filter. Untuk mengantisipasi debu halus dan produk fisi yang masih lolos dari cartridge filter, pada SPH HTTR ditambahkan komponen precharcoal trap. Desain SPH RDE sudah mengantisipasi adanya kemungkinan pengotor partikulat, baik itu debu karbon ataupun produk fisi dengan komponen filter. Cartridge filter ataupun filter dipasang pada tahap pertama SPH RDE. Produk fisi yang masih lolos dari penyaringan (filter) akan diadsorpsi menggunakan karbon aktif kondisi kriogenik pada stage paling akhir SPH.

Pengotor berbentuk gas, seperti $\mathrm{O}_{2}$ akan berdampak pada terjadinya korosi grafit di teras [6]. Komponen yang terbuat dari bahan grafit di teras adalah bahan bakar dan reflektor. Jika material grafit mengalami korosi maka material tersebut akan menjadi rapuh. Adanya gas oksigen dalam pendingin HTGR dapat diukur berdasarkan nilai oxygen partial pressure-nya. Nilai ini harus kecil untuk menjamin tidak terjadi korosi grafit. Seperti ditunjukkan pada pada Tabel 1, bahwa batasan maksimum gas pengotor yang diijinkan pada pendingin HTR-10, hanya ada 5 pengotor yang diamati, yaitu $\mathrm{H}_{2} \mathrm{O}, \mathrm{CO}, \mathrm{N}_{2}, \mathrm{H}_{2}$ dan $\mathrm{CH}_{4}$. Gas $\mathrm{CH}_{4}$ dan $\mathrm{CO}$ dalam helium akan menyebabkan reaksi karburasi material SSK reaktor. Reaksi karburasi terjadi jika unsur karbon masuk ke dalam material dan membentuk senyawa karbida $\left(\mathrm{C}_{6} \mathrm{Cr}_{23}\right)$ [6], sesuai dengan reaksi (7) dan (8):

$$
\begin{aligned}
& 23 \mathrm{Cr}+6 \mathrm{CH}_{4} \leftrightarrow \mathrm{C}_{6} \mathrm{Cr}_{23}+12 \mathrm{H}_{2} \\
& 27 \mathrm{Cr}+6 \mathrm{CO} \leftrightarrow \mathrm{C}_{6} \mathrm{Cr}_{23}+2 \mathrm{Cr}_{2} \mathrm{O}_{3}
\end{aligned}
$$

Senyawa karbida yang terbentuk akan mengakibatkan logam menjadi rapuh sehingga kekuatan mekaniknya menurun. Jika terdapat beban stress akibat tekanan dan didukung adanya temperatur tinggi operasi reaktor, akan menyebabkan terjadinya korosi retak (stress corrosion cracking). Uap $\mathrm{H}_{2} \mathrm{O}$ memberikan dampak yang berbeda dibanding $\mathrm{CH}_{4}$ ataupun $\mathrm{CO}$ terhadap logam, yaitu memberikan dampak dekarburisasi pada material SSK. Proses dekarburisasi yang diakibatkan karena reaksi $\mathrm{H}_{2} \mathrm{O}$ dengan $\mathrm{C}$ pada logam, ditunjukkan pada reaksi (9):

$$
\mathrm{H}_{2} \mathrm{O}+\mathrm{C} \leftrightarrow \mathrm{CO}+\mathrm{H}_{2}
$$

Kedua senyawa ini mengakibatkan senyawa karbida (khromium karbida/kandungan karbon dalam $\mathrm{C}_{6} \mathrm{Cr}_{23}$ ) yang terbentuk pada proses karburasi menjadi tidak stabil dan akan terlarut ke dalam pendingin, seperti ditunjukkan pada reaksi (10):

$$
\mathrm{C}_{6} \mathrm{Cr}_{23}+6 \mathrm{H}_{2} \mathrm{O} \leftrightarrow 23 \mathrm{Cr}+6 \mathrm{CO}+6 \mathrm{H}_{2}
$$

Ketika unsur $\mathrm{C}$ banyak yang larut ke pendingin maka mengakibatkan kekuatan material berkurang. Korosi grafit terjadi ketika $\mathrm{H}_{2} \mathrm{O}$ terbawa sampai ke teras. Di dalam teras, $\mathrm{H}_{2} \mathrm{O}$ akan berinteraksi dengan grafit sehingga menghasilkan $\mathrm{CO}$ dan $\mathrm{CO}_{2}$. Jika kondisi ini berkelanjutan secara terus menerus maka akan terjadi kerapuhan material grafit.

Peningkatan paparan radiasi ke lingkungan selain diakibatkan karena produk fisi yang terlepas ke pendingin, dimungkinkan pula adanya $\mathrm{C}-14\left({ }_{6} \mathrm{C}^{14}\right)$. Adanya $\mathrm{C}-14$ dalam sistem pendingin primer harus diantisipasi karena akan menimbulkan dampak radiologis pada personil saat melakukan perawatan ataupun perbaikan komponen sistem primer. Terbentuknya C-14 yang merupakan pemancar $\beta$ dengan umur paruh 5730 tahun merupakan hasil reaksi pengotor $\mathrm{N}_{2}$ dan $\mathrm{O}_{2}$ dengan neutron dalam teras. $\mathrm{N}_{2}$ dan $\mathrm{O}_{2}$ bereaksi dengan neutron dalam teras 
menghasilkan C-14 menurut reaksi (11) dan (12):

$$
\begin{aligned}
& { }_{0} \mathrm{n}^{1}+{ }_{7} \mathrm{~N}^{14} \rightarrow{ }_{6} \mathrm{C}^{14}+{ }_{1} \mathrm{p}^{1} \\
& { }_{0} \mathrm{n}^{1}+{ }_{8} \mathrm{O}^{16} \rightarrow{ }_{6} \mathrm{C}^{14}+{ }_{2} \mathrm{He}^{3}
\end{aligned}
$$

Dengan meminimalkan adanya pengotor $\mathrm{N}_{2}$ dan $\mathrm{O}_{2}$ dalam pendingin maka pertambahan paparan radiasi dapat dicegah.

Pada Tabel 2, pemantauan kandungan pengotor pada pendingin HTTR pada operasi normal, ada 4 pengotor yang dipantau, yaitu $\mathrm{H}_{2} \mathrm{O}, \mathrm{CO}, \mathrm{H}_{2}, \mathrm{CO}_{2}$. Keempat pengotor ini harus dijaga pada nilai dibawah batas yang ditentukan agar korosi grafit di teras reaktor dapat dicegah [18]. Sedangkan pengotor yang lain seperti $\mathrm{CH}_{4}, \mathrm{~N}_{2}$ dan $\mathrm{O}_{2}$ tidak ditunjukkan pada tabel. Hal ini menunjukkan bahwa pengotor tersebut harus tidak ada dalam pendingin. Reaktor HTTR adalah reaktor berbahan bakar prismatik, dan proses penggantian bahan bakar berbeda dengan pebble. Tidak ada gesekan antar bahan bakar ketika proses refuelling (pengisian bahan bakar) sehingga debu karbon yang dihasilkan jauh lebih sedikit. Proses penggantian bahan bakar prismatik cenderung lebih mampu mengantisipasi adanya kebocoran udara, karena sistem perangkat bahan bakar lebih kompak, dan penggantian bahan bakar dilakukan terhadap satu perangkat utuh.

Seperti ditunjukkan pada Gambar 2, bahwa pada HTTR, setiap komponen telah disiapkan komponen regenerasinya, sehingga jika terjadi kejenuhan maka aliran akan dipindahkan secara langsung ke komponen siaga. Dengan kondisi seperti ini maka proses regenerasi tidak mengganggu fungsi $\mathrm{SPH}$ secara keseluruhan. Sedangkan pada HTR-10, proses regenerasi dilakukan dengan memindahkan seluruh aliran ke train yang siaga, tidak per komponen. Alat pengukur kandungan pengotor baik pada HTR-10, RDE dan HTTR meliputi: gas kromatografi, infrared optical analyzer, dew point analyzer dan ion chamber spectrometer. Gas kromatografi berfungsi untuk mengukur gas pengotor, infrared optical untuk mengukur gas CO dan $\mathrm{CO}_{2}$, dew point analyzer untuk mengukur kandungan $\mathrm{H}_{2} \mathrm{O}$ sedangkan ion chamber spectrometer berfungsi untuk mengukur produk gas fisi yang terbawa dalam aliran pendingin.
Berdasarkan Gambar 3, SPH RDE mempunyai 2 buah train. Pada train operasi normal ada desain redundancy rangkaian. Saat terjadi kejenuhan pada train yang sedang beroperasi (diindikasikan dengan proses pemurnian yang tidak efektif lagi), yang mana dapat dideteksi dengan konsentrasi pengotor pada keluaran $\mathrm{SPH}$, maka train yang sedang beroperasi harus diregenerasi. Berdasarkan desain SPH RDE, maka proses regenerasi akan dilakukan setelah 1000 jam operasi secara berkesinambungan. Pada saat regenerasi maka aliran dipindahkan ke train yang sedang siaga. Proses regenerasi akan dilakukan per komponen pada SPH. Filter yang telah jenuh diregenerasi dengan penggantian, oksidator $\mathrm{CuO}$ diregenerasi dengan injeksi oksigen, kolom molecular sieve diregenerasi dengan menaikkan temperatur, demikian pula kolom karbon aktif dengan kondisi kriogenik. Lepasan gas hasil regenerasi akan ditampung dalam sistem evakuasi gas, dan dikumpulkan serta dikelola sebagai limbah gas aktifitas tinggi.

Berdasarkan Tabel 4, diketahui bahwa train ini mengambil (sodetan) volume sistem pendingin primer sebesar 5\%, dengan konstanta purifikasi sebesar 0,05 per jam. Jumlah total masa helium pada pendingin primer adalah $210 \mathrm{~kg}$ [25], sehingga dengan konstanta pemurnian sebesar 0,05 maka selama 20 jam seluruh gas helium yang ada pada pendingin telah termurnikan. Laju alir pendingin primer RDE adalah sebesar 4,3 $\mathrm{kg} /$ detik dan laju aliran masa purifikasi adalah $10,5 \mathrm{~kg} / \mathrm{jam}$. Kisaran temperatur pada train pertama adalah -180 s.d $300^{\circ} \mathrm{C}$, temperatur $-180^{\circ} \mathrm{C}$ dibutuhkan oleh bed karbon aktif, sedangkan temperatur $300^{\circ} \mathrm{C}$ merupakan temperatur masuk ke SPH.

Train kedua adalah train yang digunakan pada saat kecelakan kebocoran air. Kecelakaan kebocoran air adalah masuknya uap air ke pendingin primer, diantaranya akibat pecahnya tabung steam generator. Pada saat kecelakaan steam generator tube rupture (SGTR), diasumsikan terjadi pecah tabung steam generator dengan diameter tertentu, sehingga ada sejumlah steam yang terdifusi masuk ke pendingin primer. Pada kejadian ini, reaktor scram dan secara manual proses purifikasi dipindahkan dari train satu ke train kedua. Pada train kedua, steam didinginkan dengan 
kondensor, untuk mengembunkan uap air yang terjadi, selanjutnya air dipisahkan dengan water separator dan diolah sebagai limbah cair. Jika terjadi kecelakaan SGTR, beberapa kilogram massa steam dapat masuk ke teras, dan setelah 6

jam terdifusi ke struktur grafit di teras maka dapat mengakibatkan terjadinya korosi grafit.

Tabel 5. Data Perbandingan SPH HTR China HTTR Jepang dan RDE $[17,18,25\}$

\begin{tabular}{|c|c|c|c|}
\hline Parameter & HTR-10 & HTTR & $\mathrm{RDE}$ \\
\hline $\begin{array}{l}\text { Aliran bypass inlet dari } \\
\text { pendingin primer }\end{array}$ & $5 \%$ & $10 \%$ & $5 \%$ \\
\hline Kisaran temperatur operasi & $\begin{array}{c}-160^{\circ} \mathrm{C} \text { sampai } \\
300^{\circ} \mathrm{C}\end{array}$ & $-180^{\circ} \mathrm{C}$ sampai $300^{\circ} \mathrm{C}$ & $-180^{\circ} \mathrm{C}$ sampai $300^{\circ} \mathrm{C}$ \\
\hline Kisaran tekanan operasi & $1-30$ bar & $1-41$ bar & $1-39$ bar \\
\hline Laju aliran masuk & $10,5 \mathrm{~kg} / \mathrm{jam}$ & $24,3 \mathrm{~kg} / \mathrm{jam}$ & $10,5 \mathrm{~kg} / \mathrm{jam}$ \\
\hline $\begin{array}{l}\text { Komponen } \\
\text { pemurnian }\end{array}$ & $\begin{array}{l}\text { cartridge filter, } \\
\text { kolom CuO, kolom } \\
\text { molecular sieve, } \\
\text { karbon aktif } \\
\text { kriogenik }\end{array}$ & $\begin{array}{c}\text { filter, pre charcoal trap, } \\
\text { CuOT (copper oxide trap), } \\
\text { MST (molecular sieve } \\
\text { trap), CCT (cold charcoal } \\
\text { trap) }\end{array}$ & $\begin{array}{c}\text { cartridge filter, kolom } \\
\mathrm{CuO}, \text { kolom molecular } \\
\text { sieve, karbon aktif } \\
\text { kriogenik }\end{array}$ \\
\hline Proses regenerasi & $\begin{array}{l}\text { Menggunakan train } \\
\text { stand by }\end{array}$ & $\begin{array}{c}\text { Menggunakan komponen } \\
\text { stand by }\end{array}$ & $\begin{array}{c}\text { Menggunakan train stand } \\
b y\end{array}$ \\
\hline $\begin{array}{l}\text { Masa satu siklus (sebelum } \\
\text { regenerasi) }\end{array}$ & 2000 jam & 50 hari $(\sim 1200$ jam $)$ & 1000 jam \\
\hline
\end{tabular}

Terdapat tujuh pengotor yang dipantau setiap saat pada pendingin primer RDE, yaitu $\mathrm{CO}, \mathrm{CO}_{2}, \mathrm{H}_{2}, \mathrm{H}_{2} \mathrm{O}, \mathrm{CH}_{4}, \mathrm{O}_{2}$ dan $\mathrm{N}_{2}$, seperti yang ditunjukkan dalam Tabel 4. Pemantauan terhadap pengotor ini menunjukkan bahwa kendali kualitas pendingin primer RDE dijaga dengan lebih ketat.

Baik pada HTR-10 dan HTTR menggunakan komponen utama yang sama untuk membersihkan pengotor pada pendinginnya. Perbandingan spesifikasi SPH pada HTR-10 dan HTTR ditunjukkan pada Tabel 5. Komponen-komponen itu adalah filter, kolom oksidator $\mathrm{CuO}$, kolom molecular sieve dan kolom karbon aktif kondisi kriogenik.

Pada Tabel 5 terlihat bahwa desain SPH HTTR Jepang dilengkapi precharcoal trap sebelum aliran masuk ke kolom CuOT, meskipun debu karbon yang dihasilkan dari pendinginnya jauh lebih sedikit dibandingkan HTR-10, karena berbahan bakar prismatik. Fungsi precharcoal trap adalah menyerap terlebih dahulu adanya debu yang sangat halus yang masih terlepas dari cartridge filter. Debu halus ini berukuran lebih dari 0,1 mikron, dan dimungkinkan masih terlepas dari cartridge filter. Selain itu pada SPH HTTR, temperatur kolom karbon aktif (CCT, Cryogenic Charcoal
Trap) pada stage terakhir sistem pemurnian menggunakan temperatur nitrogen cair sampai dengan $-180^{\circ} \mathrm{C}$. Temperatur ini lebih rendah $20^{\circ} \mathrm{C}$ dibandingkan pada SPH HTR-10 China. Dengan temperatur yang lebih rendah porositas karbon aktif akan semakin mengecil sehinga daya tangkap terhadap $\mathrm{N}_{2}$ dan $\mathrm{O}_{2}$ akan semakin bagus. Oleh karena itu efisiensi penangkapan $\mathrm{N}_{2}$ dan $\mathrm{O}_{2}$ semakin tinggi. Ukuran pengotor $\mathrm{N}_{2}$ dan $\mathrm{O}_{2}$ adalah paling kecil diantara gas-gas pengotor yang ada dalam pendingin HTGR, sehingga peran temperatur pada bed karbon aktif akan sangat menentukan efisiensi adsorpsinya.

Berdasar kelebihan desain SPH HTTR Jepang tersebut, maka jika diinginkan pembersihan debu lebih optimal, diperlukan tambahan komponen precharcoal trap pada SPH RDE, karena debu halus yang berukuran lebih kecil dari 0,1 mikron dimungkinkan terlepas dari cartridge filter. SPH RDE sudah mengakomodasi temperatur kriogenik untuk kolom karbon aktif sampai dengan $-180^{\circ} \mathrm{C}$, sehingga proses adsorpsi terhadap $\mathrm{N}_{2}$ dan $\mathrm{O}_{2}$ sudah optimal.

Berdasar batasan gas pengotor pendingin pada saat operasi normal, mengindikasikan bahwa HTTR Jepang lebih ketat dalam pemantauannya, terutama 
terhadap pengotor $\mathrm{N}_{2}, \mathrm{CH}_{4}$ dan $\mathrm{O}_{2}$. Ketiga pengotor ini harus tidak ada dalam pendingin (bernilai 0). Sedangkan pada HTR-10 China, pengotor $\mathrm{CH}_{4}$ masih diperbolehkan sampai dengan konsentrasi $1,0 \mathrm{~cm}^{3} \cdot \mathrm{m}^{-3}$. Pada SPH RDE, tujuh gas pengotor pada sistem pendingin yang masih diperbolehkan sampai batas tertentu, yaitu $\mathrm{O}_{2} \leq 0,02 ; \mathrm{N}_{2} \leq 0,2 ; \mathrm{H}_{2} \mathrm{O}$ $\leq 0,2 ; \mathrm{CH}_{4} \leq 0,5 ; \mathrm{CO} \leq 3,0 \mathrm{CO}_{2} \leq 0,6 ;$ dan $\mathrm{H}_{2}$ $\leq \quad 3,0 \quad \mathrm{~cm}^{3} \cdot \mathrm{m}^{-3}$. Jika menginginkan pengendalian gas pengotor yang lebih ketat, batas pengotor yang ditetapkan pada desain SPH RDE dapat mengikuti persyaratan desain SPH HTTR-Jepang.

Berdasar lamanya satu siklus operasi masing-masing SPH sampai proses regenerasi maka dapat diketahui bahwa HTR-10 China mempunyai waktu siklus yang lebih panjang yaitu 2000 jam. Sedangkan SPH HTTR dan RDE hampir sama yaitu 1200 jam dan 1000 jam. Lama satu siklus operasi desain SPH ditentukan juga oleh adanya kebocoran udara/air ke sistem pendingin. Proses regenerasi SPH dapat dilakukan ketika hasil pengukuran masukan dan keluaran sistem tidak ada perbedaan.

\section{KESIMPULAN}

Sistem pemurnian helium (SPH) pada reaktor HTGR berdaya kecil berfungsi menjaga kualitas pendingin agar dampak pengotor terhadap SSK minimal. HTR-10 menggunakan SPH dengan satu train yang digunakan pada operasi normal dan kecelakaan (post accident). Sedang pada HTTR, sistem SPH nya menggunakan dua train, yang mana train pertama untuk operasi normal dan train kedua untuk kondisi kecelakaan. Pada desain konseptual RDE, sistem SPH didesain menggunakan dua buah train, satu train untuk operasi normal dan satu train yang lain untuk kondisi kecelakaan. Komponen utama yang sama digunakan pada $\mathrm{SPH}$ ketiga reaktor adalah filter, kolom oksidator $\mathrm{CuO}$, kolom molecular sieve dan bed karbon aktif pada temperatur kriogenik. Namun, diantara ketiga desain SPH HTGR tersebut, SPH HTTR mempunyai kelebihan yaitu dilengkapi dengan precharcoal trap sebelum aliran masuk ke kolom CuOT, untuk menyerap debu halus dibawah 0,1 mikron, sehingga penyerapan debu lebih optimal. Selain itu pada HTTR juga mempunyai batasan yang lebih ketat dalam pemantauan kandungan pengotor pada operasi normal yaitu tidak boleh adanya pengotor $\mathrm{N}_{2}, \mathrm{CH}_{4}$, dan $\mathrm{O}_{2}$ pada operasi normal. Kedua parameter ini dapat diadopsi pada desain SPH RDE agar dampak pengotor terhadap SSK dapat diminimalisasi.

\section{DAFTAR ACUAN}

[1]. J.M. Beck and L.F. Pincock. "High Temperature Gas-Cooled Reactors Lessons Learned Applicable to The Next Generation Nuclear Plant”. Prepared For The U.S. Department of Energy Office of Nuclear Energy, USA, 2011.

[2]. P. Supriatna. "Kajian Awal Pemurnian Gas He Pendingin Primer Reaktor Kogenerasi”, Prosiding PPI-PDIPTN, Buku I, Yogyakarta, 14 Juli 2009.

[3]. W.R. Johnson, et al. "Interaction of Metals with Primary Coolant Impurities: Comparison of SteamCycle and Advanced HTGRs". Specialist Meeting on High Temperature Metallic Materials for Application in Gas Cooled Reactors, 1981.

[4]. Sriyono. "Kajian Pengaruh Korosi Erosi Akibat Adanya Partikel Laden Karbon Terhadap Keselamatan Pengoperasian HTGR”. Prosiding Seminar Keselamatan Nuklir, Jakarta, 2009.

[5]. B. Schlogl. "Graphite Dust in AVR", Presented at Paul Scherer Institute, Switzerland, 2009.

[6]. K. Natesan, A. Purohit, S.W. Tan. "Material Behavior in HTGR Environments”. U.S. Nuclear Regulatory Commission Office of Nuclear Regulatory Research, NUREG/CR-6824 ANL0237, 2003.

[7]. M.P. Kissane, F.P. Zhang, M.W. Reeks. "Dust in HTRs: Its Nature and Improving Prediction of Its Resuspension“, Nuclear Engineering and Design, Vol. 251, 2012, pp. 301-305.

[8]. D.V. Isakov. "Infrared Detection of Water Ingress in A Composite Laminate Crevice Based on Room Temperature Evaporation", International Journal of Heat and Mass Transfer, Vol. 86, 2015, pp 39-42.

[9]. Z. Yanhua, S. Lei, W. Yan. "Water-Ingress Analysis for the 200 MWe Pebble-Bed Modular High Temperature Gas-cooled Reactor". Nuclear Engineering and Design, Vol. 240, 2010, 30953107.

[10]. Sriyono, I. Karliana, P. Supriatna, "Analisis Proses Filtrasi Pada Sistem Pendingin RGTT200K”, Prosiding Seminar Nasional Pengembangan Energi Nuklir, Jakarta, 2012.

[11]. Sriyono, "Analisis dan Pemodelan Filter HEPA Pada Sistem Pemurnian Helium RGTT200K", Prosiding dan Presentasi Ilmiah Penelitian Dasar Ilmu Pengetahuan dan Teknologi Nuklir, Yogyakarta, Juli 2011.

[12]. Sumijanto. "Kajian Dampak Gas Pengotor Pendingin Primer Terhadap Integritas Material Struktur RGTT". Majalah Ilmiah Teknologi Keselamatan Nuklir Sigma Epsilon, Vol. 14, No. 2, Mei 2010. 
[13]. Sriyono dan Febrianto. "Desain Konseptual Sistem Pemurnian Helium Pada RGTT200K untuk Menjamin Keselamatan Pengoperasiannya", Majalah Ilmiah Teknologi Keselamatan Nuklir Sigma Epsilon, Vol. 15, No. 3, Agustus 2011.

[14]. D. Kaczorowski and J. Chapovalooff. "Material Degradation in High Temperature The AREVA-NP Corrosion Loop“, Proceedings HTR2006: 3rd International Topical Meeting on High Temperature Reactor Technology, Johannesburg, South Africa, 2006.

[15]. I. Mutoh, et al. "Corrosion Behaviour of $\mathrm{Ni}-\mathrm{Ba}_{3} \mathrm{Se}$ Superalloys at $1373 \mathrm{~K}$ in Simulated HTGR Impure Helium Gas Environment". Journal of Nuclear Materials, Vol. 207, 2013.

[16]. Z. Wu. "The Design Feature of HTR-10". Nuclear Engineering and Design, Vol. 218, 2002.

[17]. M.S. Yao. et al. "The Helium Purification System of HTR-10". Nuclear Engineering and Design, Vol. 218, 2002.

[18]. S. Hamamoto, et al. "Investigation of Chemical Characteristics of Primary Helium Gas Coolant of HTTR (High Temperature Engineering Test Reactor)". Nuclear Engineering and Design, Vol. 271,2014

[19]. T. Furusawa, et al. "Cooling System Design and Structural Integrity Evaluation" Nuclear Engineering and Design, Vol. 233, 2004, pp. 113124.
[20]. M. Ishihara, et al. "Principle Design and data of Graphite Components". Nuclear Engineering and Design, Vol. 233, 2004.

[21]. Y. Tachibana, et al. "Structural Design of Higt Temperature Metallic Components". Nuclear Engineering and Design, Vol. 233, 2004.

[22]. L.W. Graham. "Corrosion of Metallic Materials in HTR Helium Environments". Journal of Materials, Vol. 171, 1990.

[23]. T. Takeda. "Research and Development on Prevention of Air Ingress During The Primary Pipe Rupture Accident in HTTR". Nuclear Engineering and Design. Vol. 233, 2004.

[24]. S. Alimah, E. Dewita, S. Ariyanto, "Analisis Komparasi HTGR Tipe Prismatik dan Pebble Bed”. Jurnal Pengembangan Energi Nuklir, Vol. 16, No.1, Juni 2014.

[25]. Pusat Teknologi Keselamatan Reaktor Nuklir BATAN. "Spesifikasi Teknis Reaktor Daya Eksperimental (RDE)”. Dokumen No: DT 002.KRN.2014, 2014.

[26]. Pusat Teknologi Keselamatan Reaktor Nuklir BATAN. "Justifikasi Teknis Pembangunan Reaktor Daya Eksperimental (RDE)”. Dokumen No: DT 001. KRN.2014, 2014.

[27]. Siemens AG-KWU, "Technical Design Features HTR Module, Chapter 2: Helium Purification System” (as Indonesian-RDE Design Reference), Interatom, Germany, 1985. 